\title{
Correction to: Midgut Neuroendocrine Tumors with Liver-only Metastases: Benefit of Primary Tumor Resection
}

\author{
Alexandra Gangi, $\mathrm{MD}^{1}$, Nicholas Manguso, $\mathrm{MD}^{2}$, Jun Gong, $\mathrm{MD}^{3}$, Jessica S. Crystal, $\mathrm{MD}^{1}$, \\ Shirley C. Paski, MD, MSc, FRCPC ${ }^{4}$, Andrew E. Hendifar, $\mathrm{MD}^{3}$, and Richard Tuli, MD, PhD ${ }^{5,6}$ \\ ${ }^{1}$ Division of Surgical Oncology, Department of Surgery, Samuel Oschin Comprehensive Cancer Institute, Cedars-Sinai \\ Medical Center, Los Angeles, CA; ${ }^{2}$ Department of Surgery, Cedars-Sinai Medical Center, Los Angeles, CA; ${ }^{3}$ Department \\ of Gastrointestinal Malignancies, Samuel Oschin Comprehensive Cancer Institute, Cedars-Sinai Medical Center, Los \\ Angeles, CA; ${ }^{4}$ Department of Gastroenterology, Cedars-Sinai Medical Center, Los Angeles, CA; ${ }^{5}$ Department of Radiation \\ Oncology, Cedars-Sinai Medical Center, Los Angeles, CA; ${ }^{6}$ Department of Radiation Oncology, Memorial Sloan Kettering \\ Cancer Center, New York, NY
}

\section{CORRECTION TO:}

ANN SURG ONCOL (2020) 27:4525-4532

HTTPS://DOI.ORG/10.1245/S10434-020-08510-W

In the original online version of the article, the percentage for overall survival rate for resection is switched in results section of the abstract. The correct sentence is as follows:
The 5-year OS rate was $66 \%$ for the patients who underwent resection and $49 \%$ for those who did not $(p<0.001)$.

The online version of the article has been corrected.

Publisher's NoteSpringer Nature remains neutral with regard to jurisdictional claims in published maps and institutional affiliations.

The original article can be found online at https://doi.org/10.1245/ s10434-020-08510-w.

(C) Society of Surgical Oncology 2021

Published Online: 22 March 2021

A. Gangi, MD

e-mail: Alexandra.gangi@cshs.org 